\title{
La gestión del secreto en la filmografía de Alan J. Pakula
}

\section{The management of secrecy in Alan J. Pakula's filmography}

\author{
Fermín Galindo Arranz \\ Universidad de Santiago de Compostela, España \\ fermin.galindo@usc.es \\ https://orcid.org/0000-0002-2764-2121
}

\author{
David Fuentefría Rodríguez \\ Universidad de La Laguna, España \\ dfuentef@ull.es \\ https://orcid.org/oooo-0003-1012-1378
}

\section{Resumen:}

El neoyorkino Alan J. Pakula es un director cinematográfico que hizo de la gestión del secreto el elemento central de su filmografía. Su inicial experiencia como productor le ha llevado a desarrollar un estilo propio en el que lo comercial no está reñido con la calidad del relato, buscando en el suspense y la acción atractivos añadidos para el espectador. Cuenta en todas sus películas con grandes estrellas que aseguren el éxito de taquilla. Este artículo se centra, sin embargo, en el análisis de las zonas oscuras, las sombras de la versión oficial, las tramas de poder, los monstruos del subconsciente, la violencia inconfesable y otras urdimbres narrativas de su cine, que convierten la gestión del secreto en el cemento narrativo que sustenta el intrigante mundo de su filmografía.

\begin{abstract}
:
New Yorker Alan J. Pakula is a film director who made the management of secrecy the central element of his filmography- His initial experience as a producer has led him to develop his own style in which the comercial is not at odds with the quality of the story, looking for added attraction for the viewer in suspense and action. It hsa in all its films with big stars that ensure the success of the box office. This article focuses, however, on the analysis of the dark areas, the shadows of the "official versions", the power plots, the monsters of the subconscious, the unspeakable violence and other narrative warps of his cinema, which make the management of secrecy in the narrative concrete that sustains the intriguing world of his filmography.
\end{abstract}

Palabras clave:

Alan J. Pakula; director; productor; suspense; secreto.

Keywords:

Alan J. Pakula; director; producer; suspense; secrecy. 


\section{En el principio fue la producción: la colaboración con Robert Mulligan y Matar a un ruiseñor}

Antes de que el secreto y la paranoia se conjurasen en la a priori improbable filmografía de Alan J. Pakula (Nueva York, 1928), es conocida su muy próspera faceta como productor al lado del director Robert Mulligan (Nueva York, 1925). La revista Life (20/12/63), en un amplio repaso por la figura de realizadores consolidados como Billy Wilder o Robert Rossen, calificaba a Mulligan como uno de los mejores relevos generacionales del momento. Apeándolo, además, de la premisa recogida en el subtítulo, "el ego en el arte de los nuevos creadores", el texto recogía, en sus palabras, la fertilidad de su simbiosis con Pakula a la hora de aceptar guiones en equipo (Schickel, 1963, p. 158):

Not every director should write, any more tan every writer should direct. I don't write in the sense of putting words on paper in the script, but I collaborate with the writer effectively every step of the way (...). There are other draft over a period of months, until finally he and my partner, Alan Pakula (the producer half of his team), agree that 'This is it'. Then, I feel the rest is up to $\mathrm{me}^{1}$.

La forja de tal relación puede entenderse sobre todo en su contexto inicial, entre la desconfianza de Paramount ante un Pakula dispuesto a dirigir proyectos, pero cuya única experiencia hasta entonces se limitaba a la asistencia en el Departamento de Animación de Warner Bros, y un Mulligan ex marine y estudiante de Teología, que tendía a renegar del estilo de sus coetáneos de la "Generación televisiva", y que había dirigido algunos dramas para este medio muy del agrado del primero. Su primera colaboración, a petición de Anthony Perkins, fue en El precio del éxito (Fear strikes out, 1957), lo que no quita para que, en estos primeros compases, articulasen además alguna incursión en Broadway, como con la obra teatral Comes a day (1958), también a las órdenes de Mulligan.

1 "No todos los directores deberían escribir, como no todos los escritores deberían dirigir. No escribo en el sentido de poner palabras en el papel, sino que colaboro con el escritor de manera eficaz en cada paso del camino (...). Hay otros borradores durante un período de meses, hasta que finalmente él y mi socio, Alan Pakula (la mitad productora de su equipo) acuerdan que "ya está". Entonces siento que el resto depende de mí". 
Con las citadas trabas, pero con un millón de dólares del estudio en sus manos, Pakula vio en El precio del éxito su primera oportunidad para indagar en uno de sus ulteriores intereses, la psicología, intuyendo que un director próximo a su quinta podría dar forma a esta criatura inicial. Tras el rodaje, fue el propio productor quien propuso un lazo de larga duración, que si bien no pudo fructificar inmediatamente (Mulligan volvió a la televisión mientras Pakula buscaba guiones que les permitieran volver a encontrarse), sí atemperó, al menos, los desencuentros con los ejecutivos de la “major”.

Las colaboraciones siguientes, Amores con un extraño (Love with the proper stranger, 1963); La última tentativa (Baby, the rain must fall, 1965); La rebelde (Inside Daisy Clover, 1965); Contra corriente (Up the down staircase, 1967) y La noche de los gigantes (The stalking moon, 1968), en las que cristalizó el trabajo del dúo, merecen estudio aparte, aunque nos detendremos en el filme que la posteridad ha conservado con mayor celo de análisis y que mejor conecta, sin duda, los intereses formales de ambos creadores: Matar a un ruiseñor (To kill a mockingbird, 1962).

Pakula y Mulligan discutieron ampliamente sobre las distintas formas de adaptar la famosa obra de Harper Lee, quien decía de sí misma que siempre fue más como el nebuloso Boo Radley que como la pequeña Scout. Su versión primigenia, "Ve y pon un centinela”, además, presentaba a un Atticus Finch mucho menos recto y justo que el libro y la película que a la postre cincelaron, en palabras de Pardo (12/07/15), "un tremendo friso de la sociedad del Sur de Estados Unidos y, en general, de la condición humana que trata, sin alharacas estilísticas ni pretenciosidad, el racismo, la injusticia, la crueldad, los prejuicios y las normas sociales a través de los ojos de una niña de siete años”.

Quizá por ello Lee confió desde el principio en una versión "no emasculada” y cercana al original, aunque no quisiera encargarse de ella, recayendo el trabajo en Horton Foote, quien, por mediación de Pakula, logró comprimir en uno solo los tres años en que se desarrolla el texto, decisión que le dio "la oportunidad de explorar la arquitectura que ella había creado para la novela y no sentir que estaba arruinando o manipulando algo esencial” (González, 2016, p. 5). 
Acreditado el refuerzo en pantalla del papel de unos niños sin experiencia actoral previa como la mejor aportación de Mulligan, director y productor arriesgaron por un estilismo en blanco y negro, para que parte de la audiencia se reconociese en su propia infancia, ensombreciendo al mismo tiempo dicho marco temporal, situado tras el Crack del 29. De este modo, la detallada elección de Scout (Mary Badham), Jem (Phillip Alford) y Dill (John Megna) no obedeció tanto a determinados convencimientos íntimos del dúo (por ejemplo, que la naturalidad frente a la cámara se pierde al cumplir siete años), como al deseo particular de Mulligan de retener en las sombras el sentido del descubrimiento infantil, lo que también redundó en la elección del único famoso de la función, Gregory Peck, quien dio vida a Atticus inspirándose en el carácter de Amasa Coleman Lee, madre de la escritora.

Kazan también comparaba las historias con edificios al señalar que "un guion tiene que valorarse no tanto por su lenguaje como por su arquitectura y por cómo ésta dramatiza el tema", añadiendo que "nosotros, los directores, aprendemos enseguida que un guion no es tanto un texto como una construcción" (2005, p. 323). Concebida de este modo, como una película "para escuchar", sin demasiados mecanismos genéricos, y a pesar de su estructura episódica servida en bloques, la historia, que, como señalara Romero, comparte con El sargento negro (Sargent Rutledge, John Ford, 1960) el debate en torno al "discutible funcionamiento de los tribunales, y el choque cultural entre blancos y negros" (2012, p. 101), puede resultar hoy mismo igual de interesante "en el contexto de la tóxica argumentación de los partidarios contemporáneos de la política de identidades", según Laurier y Walsh (2019). Pero su verdadero valor, para nuestro estudio, reside en que, si en general las películas de Mulligan "respondían a una conciencia liberal comprometida con una voluntad de denuncia que manifestaba una sensibilidad social especial, revelada en historias realistas de personajes desconocidos, los cuales se enfrentaban a problemas contemporáneos” (Romero, 2012, p.101), Pakula abrazaría y actualizaría, a posteriori, este hilo conductor, manifestado plenamente en la película. Un hilo que en su caso se intuiría más bien en torno a las zonas oscuras, las sombras de la convivencia y de las versiones oficiales, las tramas de poder que impregnan sociedad y la política, el sueño de la razón y las culpas inconfesables, y que 
cristalizarían, como marca personal, en su ejercicio director en solitario. De hecho, y como sucederá en no pocas ocasiones en el cine de Pakula, Matar a un ruiseñor también pivota sobre un misterio de base (el que rodea a Boo Radley Robert Duvall, en su primer papel para el cine-, a quien el prejuicio retrata como un monstruo por puro desconocimiento), y un secreto que cambiará para siempre a los personajes principales: en este caso, el que lleva a la muerte a Tom Robinson (Brock Peters), ante la falsa acusación de violación de Mayella Ewell (Collin Wilcox), quien se avergüenza en realidad de haberse sentido atraída por un hombre negro.

Con el tiempo, Pakula, cuyo cine destacaría también "por la dirección de actores, la composición visual basada en un espacio dramático significativo y la preferencia por el género policíaco” (Sánchez, 2002, p. 531), haría suyas al tiempo estas constantes en torno a la complejidad psicológica o la esperanza de crear una sociedad mejor, generalmente probando las debilidades de un sistema dispuesto a olvidar demasiado pronto la injusticia, cuando no a ampararla de forma directa o velada (sobre todo velada). A todo ello, a la fluidez comunicativa entre sus personajes, y a la habitual conjura de determinados instintos, se supeditan los elementos formales de su cine, que constituye un ejemplo claro de estilo en pro del contenido, y no al revés.

Adentrémonos, por tanto, en la gestión del secreto abordada por este cineasta en torno al que, como si de uno de sus propios personajes se tratara, no existe a día de hoy demasiada información pese a su amplia trayectoria (16 películas entre 1969 y 1997), tal y como recientemente ha vuelto a poner de manifiesto Matthew Miele, director del primer y, por ahora, único documental sobre su obra: Alan Pakula: Going for truth (2019). A propósito de tan esclarecedor subtítulo, Miele ha indicado:

Pakula one said he doesn't like to gussy up film with a lot of cuts, he doesn't like to do things just for entertainment value. All his scenes are going for truth. He said that quite definitively. I wanted to capture that. Truth has a special resonance today with All The President's Men and the journalistic aspect of that film, Alan Pakula was struggling to find the truth of films ${ }^{2}$ (2019).

2 "Pakula dijo una vez que no le gusta hacer películas con muchos cortes, que no le gusta hacer cosas solo 


\section{Secretos de familia: La decisión de Sophie}

Resulta elocuente que La decisión de Sophie (Sophie's choice, 1982), uno de los éxitos de Pakula en torno a los que gravita mayor consenso, guarde un amplio marco de conexiones autobiográficas con el autor, derivadas, principalmente, de su confesión judía y de su responsabilidad en el guion, a partir de la novela original de William Styron, en la que la película se inspira.

Dos años de redacción y de escrupuloso contacto con el literato, para alumbrar su más sincera "obra de amor", como solía calificarla, no bastaron, sin embargo, para escapar del rechazo de la comunidad hebrea, a quien molestaba el protagonismo de una mujer católica en un relato sobre las secuelas del Holocausto, reavivando así la misma polémica que antes sufriera Styron, más acostumbrado a agitar conciencias como hiciera, con los críticos afroamericanos, al publicar Las confesiones de Nat Turner, su segunda gran novela.

Poco importó la controversia. Por suerte, el interés de Pakula por la adaptación rehuía cualquier toma de partido en favor, una vez más, del estudio psicológico, en este caso el de un estado límite: la culpa insuperable. Así lo explicaba en Brown, sobre el desafío real que, a su juicio, planteaba la historia: "The final evil that Styron dealt with was that the victim is made to feel responsable for being a victim. The victim is left with the guilt. The final monstrosity: to have your loved one destroyed, and you are left feeling that you are the guilty one"3 (2005, p. 238).

Tal vez por ello la película, situada en 1947, absorbe en su fuerza evocativa los largos discursos filosóficos presentes en el texto original, rescatando el postulado de Morin cuando reivindicaba que "una gran teatralidad envuelve todo plano de cine" (2001, p. 114). Hasta el punto de que, en los primeros compases, la disposición y el vitalismo luminoso del aspirante a escritor Stingo (Peter MacNicol), y la festiva apariencia de la relación entre sus nuevos vecinos, Sophie y Nathan (Meryl Streep y Kevin Kline), recuerdan, ora a personajes más cercanos a Francis Scott Fitzgerald, ora a la británica Bright Young People de los locos años

\footnotetext{
para entretenerse. Todas sus escenas buscan la verdad. Lo dijo muy definitivamente. Quería capturar aquello. Hoy la verdad tiene una resonancia especial en Todos los hombres del presidente, y en el aspecto periodístico de la película. Alan Pakula estaba luchando por encontrar la verdad de las películas".

3 "El último mal con el que lidió Styron fue que la víctima se sintiera responsable por ser una víctima. La víctima se queda con la culpa. La monstruosidad definitiva: que destruyan a tu ser querido y te quedes sintiendo que tú eres el culpable".
} 
20, ora a personajes autoconstruidos en torno a una puesta en escena que se barrunta destructiva y artificial. Se trata de un espejismo (el primero de muchos), cuya semejanza con el mundo de Jay Gatsby, dos décadas atrás, topa, como podía esperarse al término de la Gran Guerra, con otro tipo de huida hacia adelante, menos ligada al hedonismo de antaño y más a la recomposición emocional y la huida del dolor, que aquí se edifican en torno a un secreto fundamental (la imposible decisión de ella, emigrante polaca obligada en el pasado a elegir entre uno de sus hijos en los campos de exterminio) y otro más evidente (la salud mental de Nathan, cuyo empeoramiento vamos comprobando conforme avanzan los minutos).

Lo cierto es que Pakula solicitó a su director de fotografía, el muy prolífico Néstor Almendros, un tratamiento ilusorio, pictórico y vivo del presente, ilustrativo del ideal que, para Stingo, representaba el vínculo intenso y teatral de la pareja, por mucho que a ratos veamos al judío Nathan cuestionar a Sophie, en medio de sus brotes esquizofrénicos, por sobrevivir en los campos a la muerte de tantos de los suyos. En este caso, la terrible experiencia que calla el personaje de Streep cualifica y condiciona las interacciones del trío, tanto que Pakula no dudaba en tildar genéricamente a su criatura como una película “de misterio”. Indicaba el director, de nuevo en Brown:

It's a film about ghosts. And gradually [the audience discovers] what the ghosts are, what the mistery is, but only very gradually. [The screenwriter must tease] the audience to want to know more and more about what really happened... In order to create suspense, you must build an audience's interest, you must give them enough information to want more [about] Sophie...[it is] very difficult to have a film taking place in both times, past and present, in that way, and keep the suspense in both time periods strong4 (2005, p. 239).

De ahí que, en buena lógica, Pakula se emplee más en mantener el suspense en ese presente edulcorado en duermevelas que en un pasado imposible de endulzar, y que, por tanto, prefiere ir revelando poco a poco. Para ello, el guion esconde

4 "Es una película sobre fantasmas. Y gradualmente (el público descubre) qué son los fantasmas, cuál es el misterio, pero solo muy gradualmente. (El guionista debe provocar) a la audiencia para querer saber más y más sobre lo que sucedió realmente...Para crear suspense, debes generar el interés de la audiencia, debes darles suficiente información para querer más (sobre) Sophie... (es) muy difícil que una película se desarrolle en ambos tiempos, pasado y presente, de esa forma, y mantener alto el suspense en ambos períodos". 
pistas diversas que, en correlación, tienden a enturbiar más la perspectiva del espectador que la de los protagonistas, compactos casi siempre en su voluntad de vivir como "flâneurs" emocionales. Algunas de ellas, dicho sea de paso, constan al albur de las ocurrencias de los propios actores, a quien el director permitía ocasionalmente decidir la ubicación de las cámaras, como en la escena donde Nathan se refleja en varias ventanas a la vez, mientras "dirige" apasionadamente una grabación de la Novena Sinfonía, y que, en concreto, pensó Kevin Kline para aludir, soterradamente, a la psique resquebrajada de su personaje.

Más aún, como si la ocultación en sí misma fuese un ejercicio profesional, un medio de trabajo más que un fin o un simple objeto de análisis, el director profesaba curiosamente, también, un tenaz secretismo detrás de las cámaras, en orden a mejorar la cohesión entre los tres intérpretes, cuyo trabajo estaba destinado a ser la clave desde el principio. Brown relata esta metodología, tendente, en sus palabras, a mantener "fresco" el vínculo de la terna durante el rodaje, y que se materializaba mediante tratos breves y privados que, algunas veces, llegaban a sellarse entre susurros:

When scenes were filmed, Pakula would ocasionally take an actor aside and, in Kline's words, 'whisper things in between takes and tell him or her to do something that would keep the other actor fresh" (...). 'I will very often change one actor's performance by talking to the other actor [privately], asking for a change. Because if you' re working with a good actor, [he or she] will respond to the change 5 (2005, p. 262).

El resultado obtuvo reconocimiento instantáneo: la encomiable actuación de Streep retrata a una Sophie tratando de alejar, mediante su comunicación erótica con Nathan (que también queda suavizada en pantalla respecto a la novela), los recuerdos de Auschwitz (rodados en Zagreb, por cierto, en unos tonos ocres diametralmente opuestos a los de las escenas en Nueva York). Mientras tanto, la intriga sobre su pasado se sirve, como se ha dicho, de forma episódica y semioculta, desvelándose, hasta el capítulo final, en distintos apartados que suelen chocar con el punto de vista de Stingo, quien aprovecha las pausas de la

5 "Cuando se filmaban las escenas, Pakula se llevaba ocasionalmente a un actor a un lado y, en palabras de Kline, 'susurraba cosas entre tomas y le decía que hiciera algo que mantuviese fresco al otro actor' (...). 'A menudo cambio la interpretación de un actor hablando con otro (en privado), pidiendo un cambio. Porque si estás trabajando con uno bueno, (él o ella) responderá al cambio". 
pareja para enamorarse, por añadidura, de la mujer, de forma que la realidad parece quedar siempre incompleta.

$\mathrm{Ni}$ en los minutos finales se intuye que la "sentencia del Juicio Final" sea tan "serena y perfecta” como la lee el propio Stingo, de un poema de Emily Dickinson, tras contemplar a sus amigos abrazados sobre el lecho después de ingerir cianuro. Una última escena en la que Pakula quiso sugerir que el amor sobrevivía de algún modo a la tragedia, pero que, como es habitual en su cine, exige siempre a lo superviviente el coste, y el peso inasumible, de los peores secretos.

\section{La prensa y sus fuentes. Del Watergate a Rollover}

Aunque El último testigo (The parallax view, 1974) sienta las bases del cine "de conspiración”, al promover "un laberinto narrativo, efectos sonoros impactantes (...), arquitectura agresiva de acero y vidrio y un uso moderado de la banda sonora" (Kemp, 2011, p. 347), lo cierto es que Todos los hombres del presidente (All president's men, 1976) es la película más conocida de Pakula. La trascendencia del escándalo Watergate que costó la presidencia de Estados Unidos a Richard Nixon, y el extraordinario protagonismo alcanzado por los periodistas del Washington Post, Bob Woodward (interpretado en la película por Robert Redford), y Carl Bernstein (encarnado por Dustin Hoffman), han eclipsado la extraordinaria dirección de este singular film por parte de Alan J. Pakula y Robert Redford.

El guion de William Goldman y la película se atienen con rigor al orden cronológico del libro autobiográfico que escribieron Woodward y Bernstein sobre la investigación y publicación del escándalo más famoso de la historia del periodismo americano. Los protagonistas se dejan guiar por una fuente anónima, "garganta profunda” (interpretado por Hal Holbrook), que, como los guías indios, les hace seguir la pista del dinero. Alan J. Pakula rastrea las huellas como un sabueso. El espectador interioriza el estrés y la tensión de los protagonistas en la búsqueda de la verdad mientras acompaña los reiterados travellings por la redacción que se suceden un día tras otro. La oscuridad, el silencio, las sombras, las columnas y barandillas, tras las que se ocultan una y otra vez las fuentes, forman parte de la trama. La película pasa a ser un film en blanco y negro. El 
Washington Post se convierte en el faro que ilumina radialmente en la zona oscura del poder.

La ansiedad por trasladar a la opinión pública una información de alcance, por contrastar los datos, por conocer la verdad, sostiene el suspense de muchas de las secuencias. La curiosidad de ambos periodistas funciona como motor de la trama y de cada secuencia. La mayor parte de ellas termina en una decepción. Alguien pisa el freno de la pesquisa, aparecen múltiples barreras que defienden el statu quo del poder y éstas parecen no tener límites. Solo el hambre informativa de los protagonistas es capaz de derribarlas. Robert Redford puso todo su empeño en protagonizar esta historia, en la que una pareja de simples periodistas alcanza a derribar la presidencia de Richard Nixon. Adquirió los derechos del libro de Woodward y Bernstein. Buscó a Dustin Hoffman para que le diera la réplica y a Alan J. Pakula para que llevara la dirección del film.

La investigación sobre el Watergate ejemplifica el periodismo de investigación entendido como el trabajo del periodista “en busca de la verdad” (Larrea, 2011, p. 11). El 17 de junio de 1972 comienza la investigación sobre un asunto que a la postre cambiará la historia de Estados Unidos con la dimisión de Nixon el 8 de agosto de 1974. El film aparece entonces pegado a la actualidad política, buscando la máxima fidelidad a los personajes y los escenarios. Llegando a reproducir en pantalla la vida de los periodistas en la misma sede del Washington Post. Su redacción fue reconstruida minuciosamente en el estudio, hasta lograr un acabado casi documental. En este caso, el parecido logrado con la realidad es una coincidencia en estado puro. El acabado excepcional del trabajo fue reconocido con cuatro Oscars de la Academia en 1976: Guion Adaptado, Dirección Artística, Sonido y Actor Secundario para Jason Robards, por su interpretación de Ben Bradlee. Los actores trabajaron con los personajes reales hasta mimetizarse con ellos. Con el tiempo, el sonido de las viejas máquinas de escribir disparando sus tipos en primer plano se ha convertido en un icono de la libertad de prensa. Las salvas que saludan la reelección de Nixon sirven para cerrar la historia con la pequeña pantalla como testigo de una vida política herida de muerte.

En Rollover (1981), Pakula intentaría repetir este efecto para subrayar una clave numérica secreta: 21214. Esta vez con un resultado decepcionante. Se estrenó en 
español con el título Una mujer de negocios, de nuevo un thriller que, respaldado por el star system del momento, con Jane Fonda y Kris Kristofferson, se apoyaba en una trama conspirativa y secreta, esta vez en el oscuro mundo de la élite financiera. Jane Fonda es Lee Winters, una mujer de negocios, una actriz que hereda una participación mayoritaria en una gran empresa cuando su marido es asesinado. A partir de aquí, el espectador acompaña al personaje en el tenebroso escenario de las finanzas internacionales posterior a la crisis del petróleo. En Rollover, Pakula anticipa una enorme crisis en el escenario de la globalización financiera y los oscuros manejos y tensiones a los que la economía mundial puede verse sometida. De nuevo recurre al contraste entre la visión de la realidad que aparece en los informativos televisivos con aquella que nos muestra la peripecia de la protagonista. El conocimiento del secreto cuesta la vida a aquellos que lo alcanzan, y sitúa al espectador fuera de la zona de confort de los valores dominantes y de las versiones oficiales. Antonia Laborde, por su parte, sitúa el origen del activismo de Fonda en Klute (1971): "Interpretar a una prostituta en la película de Alan J. Pakula la llevó a un sitio oscuro que no había visitado hasta entonces. Comenzó a entender el feminismo y la urgencia de protestar contra las injusticias sociales" (Laborde, 2019). Se había hartado de ser considerada la Novia de América. A día de hoy continúa manifestándose semanalmente contra el cambio climático. En noviembre de 2019, la policía la detuvo por cuarta vez en una mañana invernal en Washington. No es de extrañar, por tanto, que se atribuya a la influencia de Pakula la conversión de Jane Fonda en activista sin fronteras.

\section{El Informe Pelícano, la investigación antes de los hackers}

Un thriller comercial como El Informe Pelicano (The Pelican brief, 1992) permite asomarse a una forma de ver la actualidad en la que los más oscuros intereses intentan conformar la realidad social, utilizando el asesinato selectivo y todo tipo de estratagemas para llevar adelante sus fines. Desde las páginas de El País, Manuel Jabois (10/11/19) se preguntaba de forma retórica "¿Es Hollywood un ventilador de ideas izquierdistas?”. La aproximación al cine más comercial de Alan J. Pakula y al best seller de John Grisham no dejan lugar a dudas: 
El presidente del Tribunal Supremo era John Runyan, un duro conservador nombrado por los republicanos y odiado por los indios, así como por la mayoría de las demás minorías. De los nueve jueces, siete habían sido nombrados por presidentes republicanos. Hace quince años que Rosenberg esperaba la llegada de un demócrata a la Casa Blanca. Quería, necesitaba jubilarse, pero no soportaba la idea de que un derechista como Runyan ocupara su preciado cargo. Estaba dispuesto a esperar. Permanecería aquí en su silla de ruedas y respirando oxígeno, para proteger a los indios, los negros, las mujeres, los pobres, los minusválidos y el medio ambiente, hasta cumplir los ciento cinco años. Y nadie en el mundo podía impedírselo, a no ser que lo asesinaran (1992, p. 11).

Los mimbres para un relato de intriga jurídica ya están servidos. Otra vez, como en la mayoría de las películas de Pakula, la mujer encarna a la justicia. En este caso, Julia Roberts actúa ahora como defensora de la verdad que se esconde tras el asesinato simultáneo de los jueces del Tribunal Supremo Rosenberg y Jensen. Roberts da vida, en concreto, a una estudiante de Derecho, Darby Shaw, intuitiva, independiente y valerosa, capaz de dar la vuelta al sistema judicial americano con un trabajo académico: el Informe Pelícano. Su hipótesis resultaba un tanto exagerada o excéntrica a comienzos de los noventa, pero a día de hoy, tres décadas después, es de clamorosa actualidad. El respeto al medio ambiente se interpone en los intereses de una multinacional sin escrúpulos que cuenta con la taimada actitud de algunos prebostes del sistema judicial. La trama está servida. Una heroína, una causa y una conspiración. Alan J. Pakula maneja el suspense con maestría. El espectador asiste a crímenes ejecutados con destreza y discreción por auténticos profesionales, y participa del riesgo del conocimiento del secreto por parte de nuestra heroína. Su pareja, Thomas Callahan, profesor de Derecho Constitucional de la Universidad de Tulane, es Sam Shepard, un docente en horas bajas, deprimido y deprimente a un tiempo, quien es sorprendido por la sagacidad de su pareja, al hacerle ver la urdimbre que se esconde tras una serie de luctuosos acontecimientos que afectan a sus mentores.

El olfato del personaje de Roberts guía su pesquisa desde la intuición, acudiendo a archivos y bibliotecas, revolviendo entre legajos y sentencias en busca del hilo que enhebre los acontecimientos. Antes de internet, y de la aparición de los hackers, conseguir la información para cruzar las variables adecuadas era cosa de locos. Philip Meyer se dedicaba entonces a predicar el Periodismo de Precisión 
desde las aulas de Harvard (Galindo, 2003, p. 54), pero éste apenas se asomaba por las redacciones de algunas cabeceras con algunos reportajes de mérito basados en cruces estadísticos. En la película, Julia Roberts indaga en el porqué de las cosas, y va más allá de las fatalidades que acontecen a algunos jueces del Tribunal Supremo. Su hipótesis resulta verosímil y ella empieza a creérsela cuando su propia vida pasa a estar amenazada. A partir de ahí, la persecución está servida. Los golpes de efecto, los picados recurrentes, el barullo de Nueva Orleans. La verdad está en peligro y solo la opinión pública, el conocimiento público de la conspiración, puede salvar a nuestra heroína. Finalmente, Denzel Washington acudirá presto al socorro de la intrépida Julia en busca del happy end más comercial. El productor se impone al director, aunque sea el mismo Pakula. El filme responde al tópico del cine estadounidense en el que un aliento puramente comercial se combina con una visión progresista de los acontecimientos narrativos. Las minorías, las mujeres armadas únicamente por su sentido de la justicia o de una ética profesional a prueba de bombas, se enfrentan con un mundo siniestro y depredador, defensor de los más ocultos intereses. La defensa del medio ambiente y de las especies amenazadas, además, son utilizadas como banderín de enganche en un mundo que empieza a mostrar cierta sensibilidad por un asunto que todavía no ha tocado la conciencia planetaria debido a los perversos efectos del calentamiento global. Hay que esperar un par de décadas para que Stieg Larsson revele al mundo, con su saga Millennium, un mundo oscuro y violento junto al Báltico. La trilogía emerge de una violencia cifrada en términos sociales en la que aparece una nueva y singular heroína, Lisbeth Salander, una hacker que encuentra en la realidad virtual su medio natural. Si Julia Roberts hubiera tenido acceso a las bases de datos digitalizadas, y a las redes sociales actuales, todo hubiera sido más fácil. Por eso la visión desde la actualidad de este filme resulta apasionante. Primero, en la investigación sobre la hipótesis inicial; luego, en las barreras y dificultades para mostrar sus descubrimientos; más tarde, en las sucesivas secuencias de suspense y tensión que vive el espectador para alcanzar un final feliz y virtuoso, en el que el bien se impone en la medida en que la opinión pública alcanza a conocer la trascendencia del secreto encerrado en The Pelican Brief. 


\section{Las heroínas y sus razones ocultas. Klute y Llega un jinete libre y salvaje}

Si bien algunas voces han puesto de manifiesto la querencia y habilidades de Pakula para trabajar con actrices y personajes femeninos individualistas, y de personalidad compleja, suele ser, como hemos visto, su rol de catalizadoras el que, en puridad, dimensiona la filmografía del autor.

En el segmento específico de los años 70, además, ese papel es indistinguible del género de la cinta o del tiempo en pantalla que se concede a las mujeres, desde la breve presencia de Lee Carter (Paula Prentiss), en El último testigo, a la pugna entre Marilyn Holmberg y Jessica Potter (Jill Clayburg y Candice Bergen), que vertebra la exitosa Comenzar de nuevo (Starting over, 1979). Sin embargo, si nos atenemos a posiciones impregnadas de un idealismo más o menos velado por la privacidad, y por las razones ocultas, el rostro visible de la disidencia, que sazona por añadidura las catarsis mediante su participación en Klute, y en Llega unjinete libre y salvaje (Comes a horseman, 1978), lleva en solitario, insistimos, el nombre de Jane Fonda.

De fulgor discreto en su época, aunque referente a la postre para gigantes actuales del thriller "contenido", como David Fincher, Klute alberga un doble epítome en torno a la exploración cinematográfica del secreto: el primero, formal, en el que Pakula dispone objetos e iluminación para configurar una atmósfera paradoja del caos ordenado, y un segundo, argumental, en el que el estudio psicológico y el secretismo (más que el secreto "oficial" de la película, que se desvela pronto) fijan la senda de las relaciones inter e intrapersonales que se dan cita en la historia. Aunque en esencia respeta el tropo popular de caza al asesino, Pakula se entrega a una estética centrada "en el placer voyerista" (Del Valle, 2004, p. 541), declarando antes de la primera hora su desinterés por los misterios al uso, con una única escena para la galería que implica el señalamiento de Peter Cable (Charles Cioffi), en el momento en que una puerta corredera se cierra ante sí, tras escuchar en solitario la grabación con la que la película se inicia. De ahí que, más que en repetir arquetipos, los esfuerzos se dirijan a dotar al espacio de una cualidad sombría -que no explícitamente oscura-, apreciable incluso en exteriores (distinguibles entre Pennsylvania y Nueva York), y cuyas mejores lecturas 
cristalizan en el apartamento de la prostituta Bree (Fonda, en la primera de sus tres colaboraciones con el autor), quien prefiere iluminar con velas su intimidad, y cuya cama queda, según convenga, cubierta o rodeada de negros absolutos. Una ambientación producto del pleno entendimiento artístico entre Pakula y su director de fotografía, Gordon Willis, quien, si bien solía manifestar abiertamente sus filias y fobias, como cuando en una entrevista en American Cinematographer señaló "I think it's a vulgar color for the screen" (Schwartz, 2018), en referencia al color azul que tanto le disgustaba, al mismo tiempo era capaz, según reconocía, de materializar sus iniciales abstracciones en pos de un estilo visual que plasmase, en este caso concreto, "an inhuman scale, people feeling trivial, having lost a sense of their identity, which is the essence, to me, of the psychology of the prostitution"6 (Brown, 2005, p. 97).

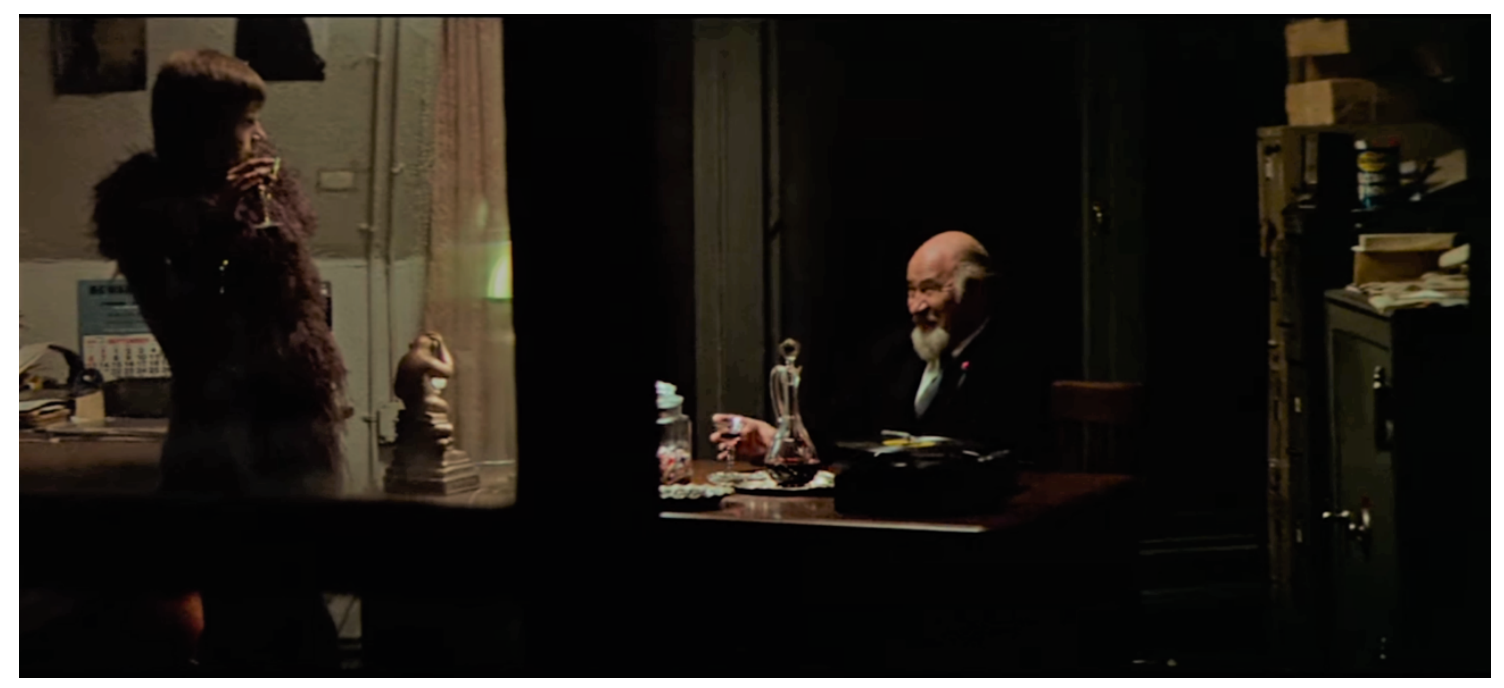

F.1: Escena del servicio de Bree (Jane Fonda) en el taller de Mr. Goldfarb (Morris Strassberg). Captura de pantalla.

Con ese tenebrismo plástico orbitando, pues, en torno al hermetismo interior de la mujer, y la cámara enfocándola desde arriba en no pocas ocasiones, Pakula construye la condición representativa del personaje frente al espejo y frente a sus clientes. En este sentido, a las celebradas escenas de diálogo con su psicoanalista -en las que, según Tavernier y Coursodon, la actriz "se libra del estilo habitual adaptando el tono del lenguaje hablado corriente contemporáneo, y dando así

6 "Una escala inhumana, gente sintiéndose trivial y que ha perdido el sentido de su identidad, lo cual es la esencia, para mí, de la psicología de la prostitución”. 
una convincente impresión de improvisación" (1997, p. 828)- se une otra, igual de asertiva con estos principios, pero mucho más sutil. Se trata del servicio en el taller de costura del viejo Goldfarb (Morris Strassberg), durante el cual el director divide el plano en dos mediante una puerta de cristal, situada a la izquierda, de modo que podemos ver a Fonda moverse a ambos lados (F1), mientras relata lentamente un cuento erótico, pero se desnuda tan solo cuando avanza a la derecha, quedando de este modo encuadrada frente a quien le paga, sin la protección alegórica del cristal a ojos del espectador.

Como Sophie, Bree se ha desnortado en el conocimiento de sí misma, aunque, en este caso, el sigilo y la incógnita pesan por igual en todos los personajes, naturalizando ese arco secretista argumental que, como decimos, resulta indisoluble del formal: Cable comete un doble crimen porque intuye una opinión oculta en Tom Gruneman (Robert Milli), amén de para guardar sus propios secretos; Klute (Donald Sutherland) brilla en su inexpugnable parquedad dialógica, y el viaje personal de Bree parte, precisamente, de ese hueco en su introspección, que le induce a buscar consejo profesional.

Así las cosas, cabe destacar que los distintos hilos conductores que han relacionado el misterio o el secreto en Pakula con cuestiones políticas -tanto aquí como en El último testigo, o en Todos los hombres del presidente, los culpables anidan en la cúspide social-, e incluso con cuestiones sexuales (como forma de control propio o ajeno), sitúan a Klute como el más privado de todos los experimentos sobre la privacidad ejercidos, en este período, por el autor neoyorquino. Es más, dentro de la celebrada “Trilogía de la Paranoia”, que Klute completa con los filmes mencionados, los personajes comparten, decididamente, "a shared cynicism about their world that only grows as they learn the truth about power"7 (Castillo, 2020).

Por su parte, la heroína de Llega un jinete libre y salvaje también guarda un secreto, pero éste no vertebra su personalidad, aunque sí condiciona su odio hacia Jacob Ewing (Jason Robards). La ranchera Ella Connors (Fonda) es una "miraestrellas", tal y como la califica el buen Dodger (Richard Fansworth); una mujer educada para luchar por sus tierras sin mirar atrás, y sin reparar en el paso

7 “Un cinismo compartido sobre su mundo, que solo crece conforme aprenden la verdad sobre el poder". 
del tiempo (es decir, un personaje recurrente del western clásico, y también del “crepuscular” que nos ocupa). Pese a que el productor, Irvin Wrinkler, nunca ocultó el desafecto de Pakula por el género (la película es la única “no urbana” del director), son de hecho dos los lugares comunes que conjura esta otra clase de western, deliberadamente anacrónico, situado, como "Sophie", al término de la Gran Guerra: el del fin de una época comulgante con el orden natural, debido a los avances de la industria (ganado frente a petróleo, esta vez, como sinónimos de libertad y poder), y el del extraño que aparece in extremis para ayudar en la resolución de un conflicto territorial.

Conservador en pleno ascenso de los directores de "Nueva ola", como De Palma o Bogdanovich, Pakula traslada estas y otras tensiones a todos los escenarios, destacando el renovado papel que juegan paisajes y panorámicas, rodados en Panavisión. Si bien su amplia presencia podría interpretarse en principio como parte de ese homenaje a los cowboys y su leyenda, en rigor puede apreciarse que la mayor parte de las escenas en campo abierto no solo alejan el horizonte físico de las montañas, sino también los anhelos particulares de paz, al desarrollarse siempre en climas de pugna, melancolía o despedida, salvo cuando muestran el productivo trabajo en equipo de Ella, y de sus compañeros, donde sí brilla la nostalgia por el Viejo Oeste.

Ese Oeste que fue, y que Pakula rescata, recordemos, en una época propensa a la parodia de algunos géneros canónicos, parece concentrarse mejor en las relaciones entre personajes, llenas de miradas sostenidas, silencios beligerantes y rudos aforismos, consustanciales a las casi siempre herméticas razones que guiaban a los vaqueros del cine, pero actualizadas aquí bajo el habitual prisma pakuliano. Como indica Lazic, “Comes a Horseman explores the same topics as the paranoia trilogy, but does so by delighting in all the things that greedy, corrupt, decentralised and unaccountable power have destroyed"8 (2020).

Los valores paternos (y por supuesto el secreto personal) de la protagonista la abocan a una vida ascética, cuya mera presentación en los primeros instantes frente a Ewing, ex amante y enemigo declarado, escenifica el ceremonial de un

8 "Llega un jinete libre y salvaje explora los mismos temas que la trilogía de la paranoia, pero lo hace deleitándose con todas las cosas que el poder ambicioso, corrupto, descentralizado he irresponsable ha destruido". 
duelo en el que ella no pronuncia una sola palabra. El peso de aquella relación sexual lleva a Ella a odiar la compañía y el ruido, y a comer con un libro en las manos, lo que estimula también la cautela de Frank (James Caan), quien deberá ganarse a cada paso la confianza de la mujer, siendo ella la que marque los tiempos de una relación amorosa seca y complicada, pero cuyo muro final es derrumbado de forma muy simple, cuando el hombre pasa por encima del secreto revelado, abordándolo sin concederle importancia.

El secreto, por último, parece ejercer su propio peso también en Ewing, de quien se desprende (pese a la planicie psicológica del personaje, "malo" de manual en comparación con la protagonista) que nunca ha abandonado su deseo por ella, habida cuenta del modo en que relata las insistentes miradas que precedieron a su encuentro de juventud, sin que la intensidad de las mismas varíe un ápice en la edad madura, y a pesar de su férrea enemistad.

\section{La tensión del espectador y otros testigos incómodos: Presunto inocente}

Una última y relevante cuestión merece abordaje, a propósito del tempo narrativo de Pakula: el contrapeso entre los aspectos del secreto que el director cede al control del público, y los que adjudica o regatea a sus personajes dentro de la trama. El thriller jurídico Presunto inocente (Presumed innocent, 1990) plantea un juego de espejos que empieza y termina con una voz en off, sobre un plano de los banquillos vacíos del jurado, donde el fiscal Rusty Sabich (Harrison Ford) defiende al principio la necesidad de conocer toda la verdad, y acaba sublimando, antes de los créditos finales, la cualidad salvífica del secreto. El ministerio público y las virtudes presupuestas, frente al peso absoluto de la vida privada, van a confrontarse una vez más, como podrá suponerse, durante todo el periplo intermedio.

Pakula no aceptó el guion inicial de Frank Pierson, en torno a la adaptación del best-seller de Scott Turrow, que, en primera instancia, iba a dirigir Sidney Pollack en un tono mucho más cercano a la todavía lejana Instinto básico (Basic instinct, Paul Verhoeven, 1992). Queriendo hacer del material original una pieza monolítica sobre la ley y el orden, y sobre la expresión de la justicia como una 
forma de sentido (igual que hiciera anteriormente con el periodismo), el autor, convertido en coguionista por primera y única vez, tuvo que conjugar un argumento recurrente del cine negro y el thriller (hombre recto cae en desgracia por la obsesión hacia una mujer) con el hecho de que buena parte del público lector conocía, esta vez, el desenlace del relato.

En efecto, si bien Roger Ebert (2005, p. 324) halló a posteriori un guion "sutil”, y una película "tranquila, inquietante y reservada", no era un secreto que el asesino de la amante de Rusty, Carolyn Polhemus (Greta Scacchi), no era él, acusado y procesado, sino su mujer, Barbara (Bonnie Bedelia). Aun así, la productora pidió a la prensa y al resto de críticos que no revelasen si Ford era o no inocente, y se rechazó, en la redacción final, introducir confesión alguna en la larga secuencia del juicio. De nuevo con Gordon Willis al servicio de muchos primeros planos, el control total de la cámara por parte de un Pakula estático, y un Ford aceptando todas las limitaciones, la cinta inspecciona ante todo, y en la forma episódica acostumbrada, los marcos mentales del protagonista, a quien no le gusta hablar de sí mismo pero cuya inmadurez se revela a la hora de sucumbir ante Carolyn, de la que se enamora al instante.

Mientas que, para su mujer, Rusty es "un libro abierto", su rigidez inmadura choca frontalmente con la moral disipada de Carolyn, arribista y "mal asunto" en general, según el detective Lipranzer (John Spencer), cuya condición de mujer fatal sin matices va descubriéndose igualmente poco a poco, dentro de una nebulosa de mentiras y de sexualidad desatada con quien le sea preciso para conseguir, en cada momento, sus objetivos.

Bajo la premisa de que todo el mundo miente, y de que siempre cabe una duda razonable, Pakula centra de nuevo en las miradas su juego de secretos, y en los entornos que los gritan a voces (como en las fugaces vistas de los largos desconchados en las oficinas, símbolo de la naturaleza humana que corrompe la aspiración utópica de la justicia). En este caso, la privacidad constituirá poco menos que una condena eterna para el personaje de Ford, quien a la revelación pública de su aventura se une la obligación de guardar, tras su absolución, el secreto del asesinato, con cuya autora deberá vivir el resto de su vida. 
Cabe establecer una rápida comparativa final en torno a esos juegos de miradas que articulan los secretos del protagonista (la primera vez que ve a Carolyn, el momento en que se acuesta con su mujer) con los del terrorista Frankie McGuire (Brad Pitt) en La sombra del diablo (The Devil's own, 1998), la última película del autor. La conceptualización visual del secreto gestionado pasa, para Pakula, por hacer que los ojos de los personajes hablen más que las palabras que les roba, bien su condición introspectiva (en el caso de Rusty), bien una dura crianza, en el de Frankie, por ejemplo en el momento del asesinato de sus padres, en la primera cena en casa de Tom O’Meara (de nuevo, Ford), o en misa, durante la confirmación de una de sus hijas. La diferencia, para Pakula, estriba en que, en La sombra del diablo, el personaje socializa en su fuero interno el hecho de "vivir con fantasmas", para sostener los suyos propios y situarse al margen de la ley. Unida a este razonamiento la revelación de que nada va a terminar bien, "al tratarse de una historia irlandesa", Pakula actualiza la naturaleza testifical del espectador hasta el punto de concederle complicidades específicas, como el momento en que la cámara desciende en un gesto casi inconsciente hacia donde está el dinero escondido por Frankie, mientras Tom lo busca en el sótano a pesar de que, para entonces, conocemos de sobra el escondite. La sombra del diablo y Presunto inocente comparten una cuita última, no menos importante: cuando los peores secretos salen a la luz, en los minutos finales, la honestidad que queda entre aquellos que han sobrevivido al secreto, o se ven obligados a hacerlo, es tan total y absoluta como irreparables sus consecuencias.

\section{Conclusiones. La gestión del secreto y el arte de Alan J. Pakula}

Como hemos visto, arte cinematográfico y gestión de la privacidad van unidos en la filmografía de Pakula, tanto en la construcción y relaciones intrínsecas de los personajes de ficción, como en su administración material y extrínseca hacia los espectadores de cine. Partiendo en muchas ocasiones de un material escrito previo, desde Todos los hombres del presidente hasta Presunto inocente o La decisión de Sophie, Pakula propone largos recorridos en clave psicológica por la mente de individuos que, de cara a la galería, resultan monolíticos en sus actitudes o convicciones, pero que albergan siempre concavidades y huecos en los 
que sobra espacio para analizar, tanto las infinitas contradicciones que habitan el ámbito personal-subjetivo, como las repercusiones sociales y/o políticas de la imperfección humana. Cuando los telones caen, además, Pakula libera de algún modo todas las presiones iniciales de lo externo para que, igualmente, los implicados o sometidos a la privacidad aparezcan con un rostro nuevo y totalmente apeado de los lastres iniciales, igual que quedan descubiertas (y por lo general denunciadas) las circunstancias del entorno que fuerza el secretismo, bien pertenezcan a un ámbito reducido (el pasado familiar o la propia personalidad), bien se relacionen con causas de mayor o menor envergadura, pero siempre susceptibles de defensa.

Como hemos visto, también, en el mismo carácter de Pakula descansa la necesidad de gestionar el secreto, actitud que transfiere a su ejercicio profesional desde el primer momento, tanto en la ideación de sus películas como en la selección de textos para adaptaciones (cuando los hay) y en los procesos de desarrollo del guion, incluso cuando ha buscado para ello adláteres de probada competencia, como en el caso de Redford en Todos los hombres del presidente.

Pakula ha imbricado igualmente el secretismo en el trabajo con la dirección de actores, una vez iniciado el rodaje, imprimiendo una dosis de angustia en la representación de los personajes, y potenciado la idea de lo privado en todos los procesos de dramatización, además de con las técnicas del montaje y de la dirección de fotografía. Incluso en aspectos externos a priori, como la promoción, Pakula ha solicitado en ocasiones que no se desvelen ciertos detalles de la trama, condicionando incluso a la crítica y consagrando, con ello, la instrumentalización del sigilo como herramienta procedimental.

El espectador, que asiste con amargura al continuo descubrimiento de verdades oscuras, paga siempre, por último, el precio de quedar con un retrogusto agridulce y una incomodidad producto de la reflexión ante el desamparo que producen los sistemas de poder, aun cuando, en todas sus películas, la justicia, representada siempre por los más débiles (el estudiante, la granjera, el trabajador...), termina imponiéndose a unos poderes cuyo entendimiento suele resultar inabarcable, porque la duda planea -siempre lo hará- sobre su verdadero alcance. 


\section{Referencias bibliográficas}

Bernstein, C. \& Woodward, R. (2017). Todos los hombres del presidente. Barcelona: Los libros del Lince.

Brown, J. (2005). Alan J. Pakula. His films and his life. New York: Back Stage Books.

Castillo, M. (14 de agosto de 2020). What the Paranoid `70s Thrillers of Alan J. Pakula can teach us about 2020. Inside Hook. Recuperado de: https://www.insidehook.com/article/movies/alan-j-pakula-1970sthriller-teacsus-about-present

Del Valle, D. (2004). Klute (1971). En S. J. Schneider (Ed.), 1001 películas que hay que ver antes de morir (p.541). Barcelona: Grijalbo.

Ebert, R. (27 de julio de 1990). Presummed Innocent. Rogerebert.com. https://www.rogerebert.com/

Galindo, F. (2003). Ámbitos del Periodismo de Precisión. Santiago de Compostela: Tórculo.

González, J. C. (6 de marzo de 2016). Inocencia preservada: Matar a un ruiseñor, de Robert Mulligan. Revista Generación, suplemento del periódico El Colombiano. Recuperado de: https://www.tiempodecine.co/web/matara-un-ruisenor-del-libro-al-cine/

Grisham, J. (1992). El Informe Pelícano. Barcelona: Planeta.

Jabois, M. (19 de noviembre de 2019) ¿Es Hollywood un ventilador de ideas izquierdistas? $\quad E l \quad$ País. Recuperado de https://elpais.com/elpais/2019/11/o8/ideas/1573239884_109102.html

Kazan, Elia (2005). En qué consiste ser director. En J. Kagan (Ed.), La mirada del director. Entrevistas con directores de cine (pp. 323-338). Madrid: Plot Ediciones.

Kemp, P. (2011). Cine. Toda la historia. Barcelona: Blume.

Laborde, A. (10 de noviembre de 2019). Actriz de puño en alto. El País. Recuperado https://elpais.com/elpais/2019/11/o8/ideas/1573211042_322121.html

Larrea, C. (2011). En busca de la verdad. Riobamba: UNACH.

Laurier, J. \& Walsh, D. (11 de abril de 2019). En defensa de To Kill a Mockingbird (Matar a un ruiseñor): película de 1962 que vuelve a los cines esta semana. World Socialist Web. Recuperado de https://www.wsws.org/es/articles/2019/04/11/mock-a11.html

Lazic, E. (7 de abril de 2020). In praise of Comes a Horseman, Alan J. Pakula's neglected western. British Film Institute/Features. Recuperado de https://www.bfi.org.uk/features/praise-comes-horseman-alan-jpakulas-neglected-western

Lee, H. (2021). Matar a un ruiseñor. New York: Harpercollins. 
Lee, H. (2017). Ve y pon un centinela. New York: Harpercollins.

Meyer, P. (1993). Periodismo de Precisión. Barcelona: Bosch.

Morin, E. (2001). El cine o el hombre imaginario. Barcelona: Seix Barral.

Pardo, P. (12 de julio de 2015): El ruiseñor vuelve a volar. El Mundo. Recuperado de

https://www.elmundo.es/cultura/2015/07/12/55a148d5e2704e93688b4 588.html

Pakula, A. J. (1950-1998). Alan Pakula Papers (Special Collections). Margaret Herrick Library (Online Archive of California, OAC). California: Online Archive of California. Recuperado de https://oac.cdlib.org/findaid/ark:/13030/c8v69kxw/entire text/

Romero, R. (2012). La pantalla de la justicia. Matar a un ruiseñor cincuenta años después. L'Atalante. Revista de Estudios Cinematográficos (14), pp. 99107.

Recuperado

de file:///C:/Users/Usuario/Downloads/La pantalla de la justicia Mata r_a_un_ru.pdf

Sánchez, J. L. (2002). Historia del Cine. Teoría y géneros cinematográficos, fotografia y televisión. Madrid: Alianza Editorial.

Sayej, N. (5 de noviembre de 2019). Finally, a documentary on filmmaker Alan J. Pakula. Forbes. Recuperado de https://www.forbes.com/sites/nadjasayej/2019/11/05/finally-a-newdocumentary-on-filmmaker-alan-j-pakula/?sh=35c1a53922e6

Schickel, R. (20 de diciembre de 1963). Just a little film to frighten you silly. Life. Recuperado https://books.google.es/books?id=QVQEAAAAMBAJ\&pg=PA10\&dq=ro bert + mulligan + movies\&hl $=$ es\&sa $=X \& v e d=2$ ahUKEwjht_zm4P_uAhULl xQKHbPsDEQQ6AEwBXoECAUQAg\#v=onepage\&q=robert\%2omulligan \%20movies\&f=false

Schwartz, H. (28 de febrero de 2018). A brilliant, often controversial cinematographer shares his considerable expertise with student filmmakers of the American Film Institute. American Cinematographer. Recuperado de https://ascmag.com/articles/flashback-gordon-willis-ascinterview-at-afi-part-i

Styron, W. (2000). La decisión de Sophie. Barcelona: Random House.

Tavernier, B. \& Coursodon, J-P. (1997). 50 años de cine norteamericano. Barcelona: Akal.

Turrow, S. (2006). Presunto inocente. Barcelona: Debolsillo. 